\title{
Gene Co-expression Analysis of the Human Substantia Nigra Identifies ZNHIT1 as an SNCA Co-expressed Gene that Protects Against a-Synuclein-Induced Impairments in Neurite Growth and Mitochondrial Dysfunction in SH-SY5Y Cells
}

\author{
Erin McCarthy ${ }^{1}$ - Aaron Barron ${ }^{1,2}$. Noelia Morales-Prieto ${ }^{1}$. Martina Mazzocchi ${ }^{1}$. Cathal M. McCarthy ${ }^{2}$. \\ Louise M. Collins ${ }^{1,3,4} \cdot$ Aideen M. Sullivan ${ }^{1,4,5} \cdot$ Gerard W. O'Keeffe ${ }^{1,4,5}$
}

Received: 23 November 2021 / Accepted: 3 February 2022 / Published online: 17 February 2022

(c) The Author(s) 2022

\begin{abstract}
Parkinson's disease (PD) is neurodegenerative disorder with the pathological hallmarks of progressive degeneration of midbrain dopaminergic neurons from the substantia nigra (SN), and accumulation and spread of inclusions of aggregated $\alpha$-synuclein $(\alpha-$-Syn). Since current PD therapies do not prevent neurodegeneration, there is a need to identify therapeutic targets that can prevent $\alpha$-Syn-induced reductions in neuronal survival and neurite growth. We hypothesised that genes that are normally co-expressed with the $\alpha$-Syn gene (SNCA), and whose co-expression pattern is lost in PD, may be important for protecting against $\alpha$-Syn-induced dopaminergic degeneration, since broken correlations can be used as an index of functional misregulation. Gene co-expression analysis of the human SN showed that nuclear zinc finger HIT-type containing 1 (ZNHIT1) is co-expressed with SNCA and that this co-expression pattern is lost in PD. Overexpression of ZNHIT1 was found to increase deposition of the H2A.Z histone variant in SH-SY5Y cells, to promote neurite growth and to prevent $\alpha$-Syn-induced reductions in neurite growth and cell viability. Analysis of ZNHIT1 co-expressed genes showed significant enrichment in genes associated with mitochondrial function. In agreement, bioenergetic state analysis of mitochondrial function revealed that ZNHIT1 increased cellular ATP synthesis. Furthermore, $\alpha$-Syn-induced impairments in basal respiration, maximal respiration and spare respiratory capacity were not seen in ZNHIT1-overexpressing cells. These data show that ZNHIT1 can protect against $\alpha$-Syn-induced degeneration and mitochondrial dysfunction, which rationalises further investigation of ZNHIT1 as a therapeutic target for PD.
\end{abstract}

Keywords Parkinson's disease $\cdot \alpha$-Synuclein $\cdot$ SNCA $\cdot$ ZNHIT1 $\cdot$ Dopamine $\cdot$ Dopaminergic $\cdot$ Substantia nigra $\cdot$ Histone deacetylase $\cdot$ Axon degeneration $\cdot$ Histone acetylation

Aideen M. Sullivan

a.sullivan@ucc.ie

Gerard W. O'Keeffe

g.okeeffe@ucc.ie

1 Department of Anatomy \& Neuroscience, University College Cork, Cork, Ireland

2 Department of Pharmacology and Therapeutics, University College Cork, Cork, Ireland

3 Department of Physiology, University College Cork, Cork, Ireland

4 Parkinson's Disease Research Cluster (PDRC), University College Cork, Cork, Ireland

5 APC Microbiome Ireland, University College Cork, Cork, Ireland

\begin{tabular}{ll}
\multicolumn{2}{l}{ Abbreviations } \\
PD & Parkinson's disease \\
$\alpha-$ Syn & $\alpha$-Synuclein \\
SNCA & $\alpha$-Synuclein gene \\
ZNHIT1 & Zinc finger HIT-type containing 1 \\
DA & Dopamine \\
DAergic & Dopaminergic \\
NT & Neurotransmission \\
LB & Lewy body \\
SN & Substantia nigra \\
TGF $\beta$ & Transforming growth factor $\beta$ \\
WT & Wild-type \\
GFP & Green fluorescent protein \\
GO & Gene ontology \\
BSA & Bovine serum albumin
\end{tabular}




\begin{tabular}{|c|c|}
\hline PBS & Phosphate-buffered saline \\
\hline PBS-T & Phosphate-buffered saline Triton X-100 \\
\hline $\mathrm{TH}$ & Tyrosine hydroxylase \\
\hline ALDH1A1 & $\begin{array}{l}\text { Aldehyde dehydrogenase } 1 \text { family member } \\
\text { A1 }\end{array}$ \\
\hline HDAC5 & Histone deacetylase 5 \\
\hline HDAC6 & Histone deacetylase 6 \\
\hline SAP18 & Histone deacetylase complex subunit SAP18 \\
\hline MORF4L1 & Mortality factor 4-like protein 1 \\
\hline $\mathrm{H} 3$ & Histone 3 \\
\hline $\mathrm{ACH} 3$ & Acetylated histone 3 \\
\hline $\mathrm{AD}$ & Alzheimer's disease \\
\hline HAT & Histone acetylase \\
\hline HDAC & Histone deacetylase \\
\hline MD & Mitochondrial dysfunction \\
\hline ROS & Reactive oxygen species \\
\hline SRCAP & SNF2-related CBP activator protein \\
\hline VDAC1 & Voltage-dependent anion-selective channel 1 \\
\hline MD & Mitochondrial dysfunction \\
\hline
\end{tabular}

\section{Introduction}

Parkinson's disease (PD) is a neurodegenerative disorder that is characterised by progressive loss of midbrain dopaminergic neurons from the substantia nigra (SN) $[1,2]$. The axons of these neurons form the nigrostriatal pathway, which innervates the striatum and is a key part of the basal ganglia circuitry which regulates voluntary movement [1,2]. Dysfunction of this nigrostriatal pathway resulting from its progressive degeneration in PD leads to motor impairments including akinesia, bradykinesia and resting tremor, which are the core clinical features of this disease [3, 4].

$\mathrm{PD}$ is a synucleinopathy characterised by the accumulation of intracellular proteinaceous aggregates, called Lewy bodies and Lewy neurites, which consist predominantly of the protein $\alpha$-synuclein ( $\alpha$-Syn), which is encoded by the $S N C A$ gene [5-7]. A definitive link between SNCA and PD came with the demonstration that mutations $[8,9]$, or duplications and triplications $[10,11]$, in $S N C A$ cause autosomal-dominant PD and that genetic polymorphisms in $S N C A$ are risk factors for sporadic PD [12-16]. Moreover, rodent neurons overexpressing $\alpha$ Syn [17], or iPSC-derived dopaminergic neurons carrying mutations, and duplications or triplications of SNCA have reduced survival and defects in neurite growth $[18,19]$. In agreement, several studies have shown nigrostriatal degeneration in rodents and non-human primates, resulting from injection of $\alpha$-Syn pre-formed fibrils (PFFs) or recombinant adeno-associated virus vector (rAAV)-mediated $\alpha$-Syn overexpression (for review see [20]). Collectively, these data show that $\alpha$-Syn accumulation plays a role in dopaminergic degeneration in PD. Therefore, it is important to investigate the genes and molecular networks that are affected by $\alpha$-Syn, in order to elucidate the molecular basis of cellular dysfunction in PD and to identify new therapeutic targets.

Gene co-expression analysis is an approach that can be used to associate genes of unknown function with specific biological processes, to prioritise candidate disease genes or to discern transcriptional regulatory programmes [21, 22]. In this study, we performed gene co-expression analysis in which we examined all possible pairwise correlations between $S N C A$ and other genes in SN, hippocampus and occipital cortex of a human brain transcriptome dataset [23], to identify genes that are uniquely co-expressed with $S N C A$ in the SN. Following an enrichment analyses, we selected genes for functional analysis depending upon whether their co-expression with SNCA was altered in PD; since normal co-expression patterns tend to break down in disease states, these broken correlations can be used as an index of functional misregulation [24-26].

We found that the gene zinc finger HIT-type containing 1 (ZNHITl) is co-expressed with the SNCA gene and that this co-expression in the $\mathrm{SN}$ is lost in PD. ZNHIT1 is a core component of the SNF2-related CBP activator protein (SRCAP) complex, which is an ATP-dependent chromatin remodelling complex that replaces histone $(\mathrm{H}) 2 \mathrm{~A}$ with the histone variant H2A.Z in the nucleosome to regulate gene expression [27, 28]. Previous studies have shown that ZNHIT1 regulates gene expression associated with mitochondrial function during prenatal cardiac development [29] and controls intestinal stem cell maintenance by regulating H2A.Z incorporation [30]. However its function in the neural cells and in the nervous system is largely unknown.

\section{Materials and Methods}

\section{Gene Expression Analysis of Human SN}

Gene expression data for healthy control human SN (GSE:60,863 [31]) were analysed using R2 Genomics Analysis and Visualization Platform [32]. This gene expression data from the GSE:60,863 dataset was generated by the UK Brain Expression Consortium. It contains gene expression data from post mortem human brain samples that were dissected from ten different brain regions. A total of $1231 \mathrm{sam}-$ ples were obtained from 134 Caucasian neuropathologically and neurologically normal individuals; the aim of that study was further understanding of gene expression regulation in the human brain [31]. Gene set enrichment analysis was carried out using STRING (https://string-db.org) and PANTHER (http://pantherdb.org) to assess which genes were significantly co-expressed with $S N C A$ in the SN. All gene expression data are presented as $\log 2$ expression values. 
Gene ontology (GO) enrichment analysis was performed using the gene ontology platform (http://geneontology.org/).

\section{Cell Culture}

Human SH-SY5Y cells (ATCC; CRL-2266) are extensively used as models of human DA neurons [33]. SH-SY5Y cells were generally plated at a density of $5 \times 10^{5}$ cells per well in a 24-well plate and grown in Dulbecco's modified eagle medium nutrient mixture F-12 (Sigma) with $10 \%$ foetal calf serum (Sigma), supplemented with $100 \mathrm{nM} \mathrm{L-glutamine}$ (Sigma), $100 \mathrm{U} / \mathrm{ml}$ penicillin (Sigma) and $10 \mu \mathrm{g} / \mathrm{ml} \mathrm{strep-}$ tomycin (Sigma). These cells were incubated in a humified atmosphere containing $5 \% \mathrm{CO}_{2}$ at $37{ }^{\circ} \mathrm{C}$. A differentiating agent was not applied as the SH-SY5Y cells develop clear neurites when cultured at low density. Furthermore, differentiating agents may cause them to become less susceptible to the effects of SNCA. SH-SY5Y cells were fixed in $4 \%$ paraformaldehyde at $72 \mathrm{~h}$ post-transfection.

\section{Plasmid Transfection}

SH-SY5Y cells were transfected using the TransIT-X2® Dynamic Delivery System (Mirus Bio, Cat \# 6000) as per the manufacturer's instructions. SH-SY5Y cells were seeded at a density of $5 \times 10^{5}$ cells per well in a 24-well plate. Where indicated, cells were transfected at 1 DIV with varying combinations of plasmids, as indicated in each figure legend: pcDNA3-EGFP (Addgene plasmid \# 13,031; a gift from Douglas Golenbock), EGFP-alpha-synuclein-WT (Addgene plasmid \# 40,822; a gift from David Rubinsztein [34]), FLAG-ZnF/HIT1 (Addgene plasmid \# 15,332, a gift from Joan Conaway and Ronald Conaway [35]), pT-FLAG (Addgene plasmid \# 31,385; a gift from Yegor Vassetzky [36]) and GFP Cignal reporter (Qiagen CCS-017G). Five hundred nanograms of each plasmid was mixed with $1.5 \mu \mathrm{l}$ of TransITX2® in $50 \mu \mathrm{l}$ of media and incubated for $30 \mathrm{~min}$ at room temperature, before being added to the cultures.

\section{Immunocytochemistry and Analysis of Neurite Growth}

Prior to imaging, cells were fixed for $25 \mathrm{~min}$ in $4 \%$ paraformaldehyde, followed by $3 \times 5$-min washes in $0.02 \%$ Triton X-100 in $10 \mathrm{mM}$ phosphate-buffered saline (PBS-T). The cells were then incubated in 5\% bovine serum albumin (BSA) in $10 \mathrm{mM}$ PBS-T for $1 \mathrm{~h}$ at room temperature. They were then incubated in one of the following antibodies: phospho-Smad 1/5/9 (Cell Signaling 13820S; 1:500), AcH3 K9-K14 (Santa Cruz sc-33361; 1:500) or ZNHIT1 (Thermo Fisher \# PA5-53,903; 1:500), diluted in $1 \%$ BSA in $10 \mathrm{mM}$ PBS at $4{ }^{\circ} \mathrm{C}$ for $16 \mathrm{~h}$. Following $3 \times 5$-min washes in $10 \mathrm{mM}$ PBS-T, cells were incubated in 594-conjugated Alexa
Fluor® secondary antibody (Invitrogen; 1:500 A11005 or $\mathrm{A} 11012$ ) in $1 \% \mathrm{BSA}$ in $10 \mathrm{mM}$ PBS, prior to $3 \times 5$-min washes. For analysis of neurite growth, six non-overlapping images were captured from each well in each experimental group, using an Olympus IX71 inverted microscope. Neurite growth was measured by opening each image in Image $\mathrm{J}$ and manually tracing the length of a given neurite using the trace function in Image J. Where indicated, the fluorescence intensity of individual cells was measured by densitometry using Image $\mathbf{J}$ analysis software. Specifically, fluorescence intensity was measured using the corrected total cell fluorescence (CTCF) method, which determines the corrected total fluorescence by subtracting the background signal and taking into account the area of the fluorescing cell. The formula used to calculate the fluorescence intensity of individual cells was $(\mathrm{CTCF})=$ Integrate Density $-($ Area of Selected Cell $\times$ Mean Fluorescence of Background). These individual cell values were then averaged to get one value per group per $\mathrm{N}$.

\section{Generation of Stable GFP and a-Syn-GFP SH-SY5Y Cell Lines}

For generation of stable cell lines, SH-SY5Y cells were plated at the density of $4 \times 10^{5}$ cells in a T-75 culture flask and transfected using TransIT-X2® Dynamic Delivery System (Mirus Bio, Cat \# 6000) as per the manufacturer's instructions, with $15 \mu \mathrm{g}$ of pcDNA3-EGFP (Addgene plasmid \# 13,031; a gift from Professor Douglas Golenbock) or of EGFP-alphasynuclein-wild-type (Addgene plasmid \# 40,822). At 72 h post-transfection, cells were exposed to $200 \mathrm{mg} / \mathrm{ml} \mathrm{G} 418$ (Sigma) allowing selection based on plasmid-specific antibiotic resistance. Stably-transfected cells were split weekly for 4 weeks, with addition of G418 until visual confirmation of fluorescent EGFP expression in all cells.

\section{Seahorse Assay to Assess Mitochondrial Function}

Mitochondrial function and metabolism were assessed using the Seahorse XF96 Mito Stress Test (Agilent Technologies). The stable GFP or $\alpha$-Syn-GFP SH-SY5Y cell lines were seeded at $4 \times 10^{5}$ cells/well in a XF96 culture plate and transfected $24 \mathrm{~h}$ later with $500 \mathrm{ng}$ of plasmid carrying either FLAG (Addgene \#31,385) or FLAG-tagged ZNHIT1 (Addgene \#15,332) for $72 \mathrm{~h}$. At $1 \mathrm{~h}$ before the assay, the media was changed to Seahorse XF DMEM media, supplemented with $2 \mathrm{mM} \mathrm{L}$-glutamine, $1 \mathrm{mM}$ pyruvate and $10 \mathrm{mM}$ glucose, and cells were allowed to equilibrate at $37{ }^{\circ} \mathrm{C}$ and $0 \% \mathrm{CO}_{2}$ for $1 \mathrm{~h}$. After calibration, oxygen consumption rate (OCR) was measured by the Seahorse XF96 Analyzer and recorded with XF Wave software 1.4.2. at 12 timepoints over the 80-min run: three times at basal respiration, three times 
after injection of $2.5 \mu \mathrm{M}$ oligomycin to inhibit complex $\mathrm{V}$, three times after injection of $2 \mu \mathrm{M}$ of the ionophore carbonyl cyanide-p-trifluoromethoxyphenylhydrazone (FCCP) to depolarize the inner mitochondrial membrane and three times after injection of $0.5 \mu \mathrm{M}$ each of rotenone and antimycin A, to inhibit complexes I and III, respectively. After completion of the assay, cells were lysed in $1 \times$ RIPA buffer, and total protein was quantified by bicinchoninic acid (BCA) assay. OCR values normalised to the amount of protein per well. From normalised OCR values, the following respiratory parameters were calculated: basal respiration, proton leak, maximal respiration, non-mitochondrial respiration, ATP production and spare respiratory capacity.

\section{Statistical Analysis}

Statistical analysis was performed using GraphPad Prism 9 (@2021 GraphPad Software, CA USA). All data are presented as the mean \pm SEM of the number of experimental replicates rather than the number of cells. Statistical differences were analysed using two-way ANOVA as appropriate, with post hoc tests as indicated in the figure legends.

\section{Results}

\section{Identification of SNCA Co-expressed Genes in the Human SN Reveals Enrichment of Genes Involved in Histone Deacetylation, and Altered ZNHIT1-SNCA Co-expression in the SN in PD}

We first sought to identify SNCA co-expressed genes that were enriched in the $\mathrm{SN}$, by performing pair-wise correlations between $S N C A$ and all other genes expressed in the human SN ( $n=101$ samples), hippocampus, $(n=122)$ and occipital cortex $(n=122)$ using open-source human brain transcriptome data (GSE:60,863) [23]). This analysis identified $n=303$ genes that were co-expressed with $S N C A$ and that were unique to the $\mathrm{SN}$ (Fig. 1A). We next enriched this gene list for those most likely to be expressed in dopaminergic neurons by comparing the $n=303$ list to those genes that were co-expressed with two dopaminergic markers, $T H$ and ALDHIAl, in the SN. We found that $n=233 S N C A$ co-expressed genes that were enriched in the $\mathrm{SN}$ were also co-expressed with $T H$ and ALDHIAI (Fig. 1B). We next used PANTHER (http://pantherdb.org) to perform a protein classification analysis, to group genes into categories in order to remove those genes involved in general aspects of cellular function (Fig. 1C); this generated a final list of $n=125$ genes. We next performed a gene set enrichment analysis using STRING (https://string-db.org) and found a significant enrichment of genes associated with the histone deacetylase complex (GO:0,000,118); these were ZNHIT1, HDAC5, HDAC6, SAP18 and MORF4LI (Fig. 1D).

We next used available transcriptome data from the SN of age- and gender-matched control and PD samples (GSE49036) [37] to examine the co-expression of the five lead genes identified from our earlier co-expression analysis with $S N C A$ in the SN in healthy controls and subsequently to determine whether their co-expression pattern with $S N C A$ is altered in PD. The rationale for doing this is that genes with a functional association are strongly coexpressed, and these normal co-expression patterns tend to break down in a disease state; therefore, broken correlations can be used as an index of functional misregulation [24-26]. To do this, we used open source transcriptome data (GSE 49,036) from a previously published report [37] that had performed microarray analysis on SN samples taken from controls $(n=8)$ and patients with PD $(n=15)$. Of the 5 lead genes identified from our earlier analysis (ZNHIT1, HDAC5, HDAC6, SAP18, MORF4L1), we validated a significant correlation between ZNHIT1, SAP18 and HDAC5 with SNCA in the $\mathrm{SN}$ of controls (Fig. 1E). In contrast, while the significant positive correlation between SAP18 and SNCA was maintained in $\mathrm{PD}\left(r=0.77, p=6.51 \times 10^{-04}\right)$, the correlations of both ZNHITI ( $r=0.13$, not significant (n.s.)) and HDAC5 $(r=0.28$, n.s.) with SNCA was lost in PD SN samples, with the greatest change in $r$ seen in SNCA-ZNHIT1 (Fig. 1E). Since HDAC5 has previously been shown to regulate $\alpha$-Syn-induced impairments in neurite growth [38, 39], we focused on ZNHIT1 in subsequent analysis, as the aim was to identify novel genes that may be relevant to $\alpha$-Syninduced impairments in cellular function.

We next investigated the correlation between the top ranked gene, ZNHITI, and SNCA in the SN of samples classified as controls $(n=8)$, Braak stage $1 / 2(n=5)$, Braak stage $3 / 4(n=7)$ and Braak stage 5/6 $(n=8) \mathrm{PD}$, to investigate at which disease state the co-expression patterns break down. We found a significant correlation between ZNHIT1 and SNCA ( $r=0.80, p=0.0160)$ in control samples; however, this correlation was lost even at the earliest Braak stages $1 / 2(r=-0.11$, n.s. $)$ and at all stages thereafter (Fig. 1F). These broken correlations suggest that there is an early and sustained functional dysregulation of SNCA-ZNHIT1 in PD.

\section{ZNHIT1 Increases Incorporation of the Histone Variant H2A.Z in SH-SY5Y Cells and This Is Unaffected by a-Synuclein Overexpression}

ZNHIT1 has been shown to regulate H2A.Z deposition and thereby modulate gene transcription [40]. H2A.Z incorporation regulates important cellular and molecular processes including heterochromatin regulation [41], DNA repair [42, 43] and transcriptional regulation [44]. Additionally, H2A.Z is incorporated into the SRCAP complex [45], an 


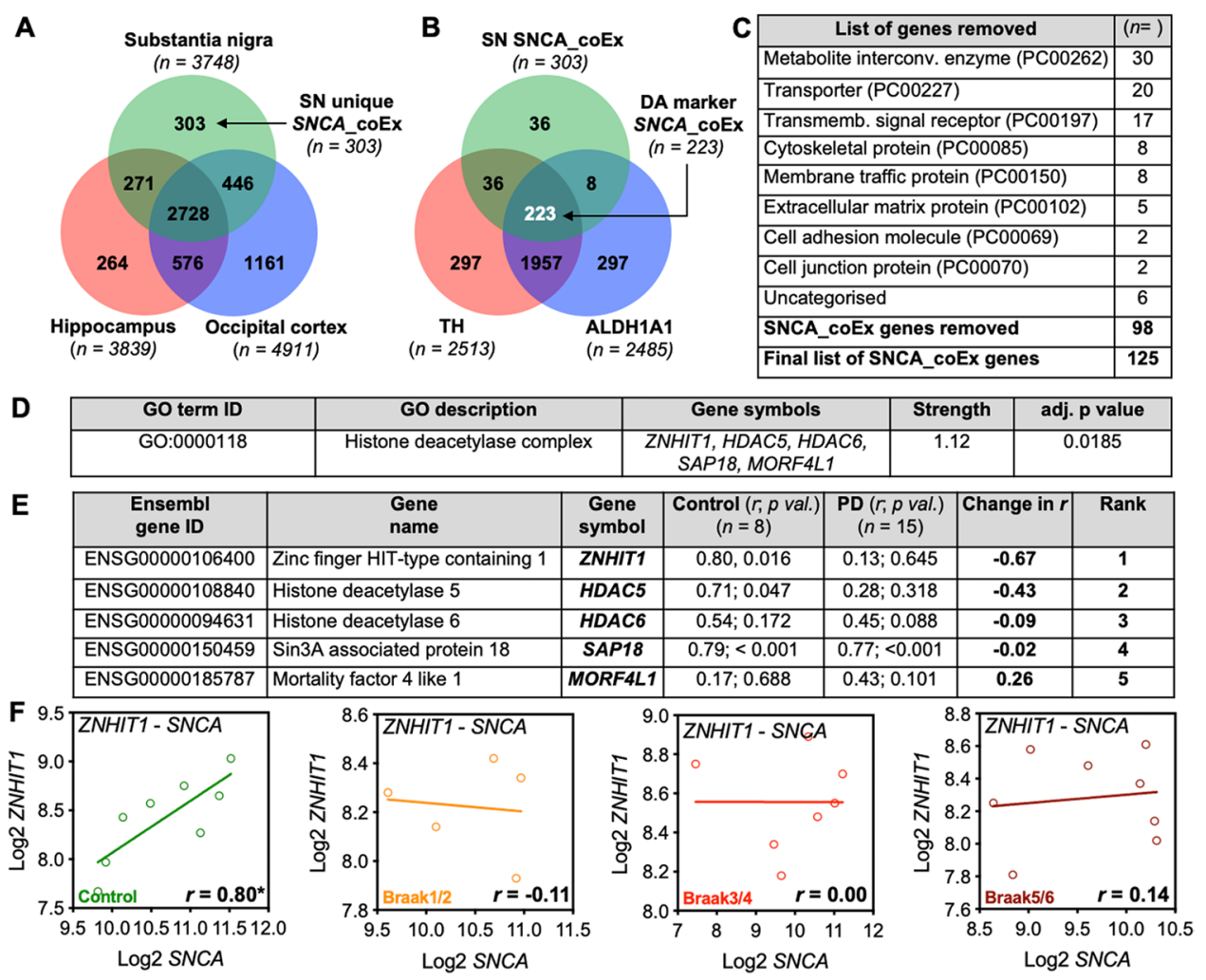

Fig. 1 Identification of SNCA co-expressed genes in the human SN reveals enrichment of genes involved in histone deacetylation, and altered ZNHIT1-SNCA co-expression in the SN in PD. A Venn diagram showing the overlap between genes with positive significant co-expression with $S N C A$ in the SN (green), hippocampus (red) and occipital cortex (blue), after Bonferroni correction. This analysis identified $n=303$ SNCA co-expressed (SNCA_coEx) genes that were unique to the SN. B Venn diagram showing the overlap between SNCA_coEx genes (green) and genes co-expressed with the dopaminergic markers $T H$ (red) and $A L D H 1 A 1$ (blue) in the SN. This analysis identified $n=223$ SNCA co-expressed (SNCA_coEx) genes that overlapped with $T H$ and $A L D H 1 A 1$ co-expressed genes. In A and $\mathbf{B}$ the total number of genes in each case is shown in parentheses. Raw data was derived from GSE60863. C The list of $n=223$ genes were classified using the Panther classification tool (http://pantherdb.

ATP-dependent complex involved in the regulation of chromatin remodelling, of which ZNHIT1 is the main regulatory component [46].

Based on this, we investigated the effects of ZNHIT1 and $\alpha$-Syn overexpression on incorporation of H2A.Z in SH-SY5Y cells. SH-SY5Y cells were transfected with plasmids expressing either GFP or GFP-tagged wild-type human $\alpha$-Syn, together with either FLAG (control) or FLAG-tagged human ZNHIT1 and found them to be cotransfected (Supplementary Fig. 1). The levels of H2A.Z, $\mathrm{H} 3$ and acH3 protein expression in GFP +-transfected cells were measured at $72 \mathrm{~h}$ post-transfection using immunocytochemistry and densitometry. Two-way ANOVA revealed a significant effect of ZNHIT1 $\left(F_{1,20}=18.97, p=0.0003\right)$ on org), and the table shows the list of functional and/or structural gene classes that were removed from the $n=223$ genes to generate a final list of $n=125$ SNCA_coEx genes in the SN. D Results of the gene ontology (GO) enrichment analysis of the $n=125$ genes, which was performed using STRING (https://string-db.org). The $p$ value was corrected for multiple testing using the Benjamini-Hochberg procedure. $\mathbf{E}$ Table showing the changes in the co-expression pattern $(r 2-$ $r 1)$ of SNCA with ZNHIT1, HDAC5, HDAC6, SAP18 and MORF4L1 in control $(n=8)$ and PD $(n=15) \mathrm{SN}$ samples. F Linear regression analysis showing the correlations between ZNHIT1 and SNCA in control $(n=8)$, Braak stage $1 / 2(n=5)$, Braak stage $3 / 4(n=7)$ and Braak stage 5/6 $(n=8)$ SN samples. The $r$ values are shown on each linear regression graph. Raw data was derived from GSE49036. All analyses were performed using the R2 genomics analysis and visualisation platform (https://hgserver1.amc.nl/cgi-bin/r2/main.cgi)

H2A.Z expression in SH-SY5Y cells (Fig. 2A, B). Post hoc testing revealed a significant increase in $\mathrm{H} 2 \mathrm{~A} . \mathrm{Z}$ expression in the ZNHIT1 + GFP group compared to the control group (Fig. 2A, B). Furthermore, there was a significant increase in H2A.Z expression in the ZNHIT1 $+\alpha$-Syn group compared to the control group, and no significant increase over control was seen in the FLAG $+\alpha$-Syn group (Fig. 2A, B). These data show that ZNHIT1 increases H2A.Z incorporation, even when co-expressed with $\alpha$-Syn.

We next examined the levels of $\mathrm{H} 3$ and levels of acetylated $\mathrm{H} 3$ (acH3), as $\alpha$-Syn has been shown to act within the nucleus to inhibit the acetylation of histone $3(\mathrm{H} 3)$ and thus to promote neurotoxicity in SH-SY5Y cells and in wildtype $\alpha$-Syn transgenic Drosophila [47]. SH-SY5Y cells 
Fig. 2 ZNHIT1 increases incorporation of the histone variant H2A.Z in SH-SY5Y cells and this is unaffected by $\alpha$-synuclein overexpression. A-F SH-SY5Y cells were transfected with $500 \mathrm{ng}$ of plasmid expressing either FLAG (Addgene \#31,385) or FLAG-tagged ZNHIT1 (Addgene \#15,332), together with a plasmid expressing either GFP or GFP-tagged wild-type $\alpha$-synuclein $(\alpha \operatorname{Syn})$ (Addgene \#40,824). All analyses were performed at $72 \mathrm{~h}$ post-transfection. A-F Graphs and representative photomicrographs of A, B H2A.Z, C, D $\mathrm{H} 3$ and $\mathbf{E}, \mathbf{F}$ acetylated (ac) H3 levels in transfected (GFP+) cells. All data are mean \pm SEM expressed as a percentage of the control (FLAG + GFP) from $n=3-6$ independent experiments. Two-way ANOVA with post hoc Fishers LSD test $(* * p<0.01, * * * p<0.001$ vs. FLAG + GFP)
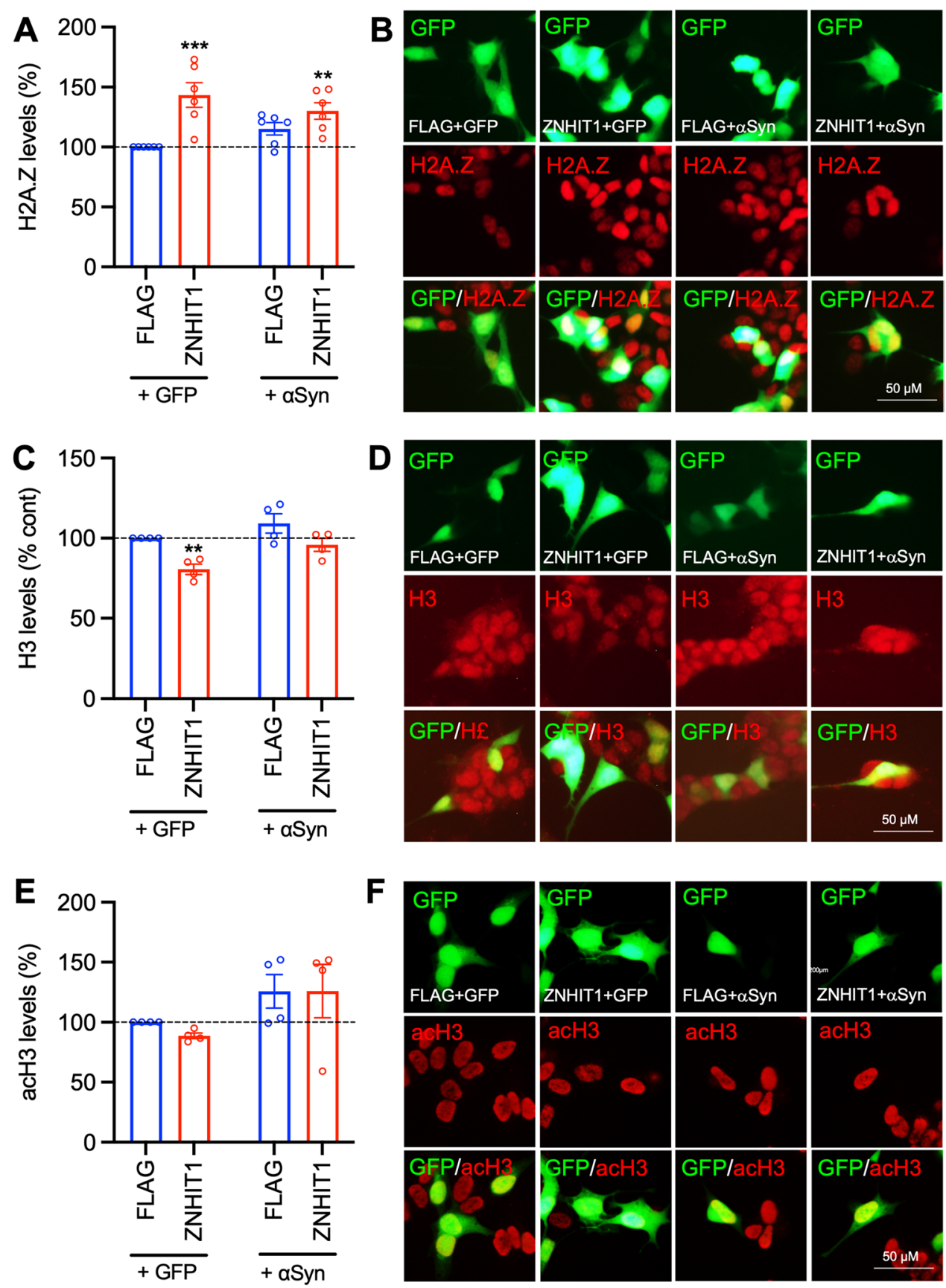

were transfected with plasmids expressing either GFP or GFP-tagged wild-type human $\alpha$-Syn, together with either FLAG or FLAG-tagged human ZNHIT1, and immunocytochemistry was performed for $\mathrm{H} 3$ or acH3 at $72 \mathrm{~h}$ posttransfection. Two-way ANOVA revealed a significant main effect of ZNHIT1 $\left(F_{1,12}=16.86, p=0.0015\right)$ on H3 levels (Fig. 2C, D). Post hoc testing showed that overexpression of ZNHIT1 significantly reduced cellular levels of $\mathrm{H} 3$, whereas no significant reduction from control levels was seen in the FLAG $+\alpha$-Syn group (Fig. 2C, D). Cellular levels of acH3 were unaffected by the overexpression of ZNHIT1
$\left(F_{1,12}=0.177\right.$, n.s. $)($ Fig. 2D, E). Collectively, these data suggest that ZNHIT1 overexpression regulates cellular levels of H2A.Z and H3, while ZNHIT1-induced reductions in $\mathrm{H} 3$ do not occur in the presence of $\alpha$ Syn.

\section{ZNHIT1 Promotes Neurite Growth and Protects Against a-Synuclein-Induced Reductions in Neurite Growth and Cell Viability in SH-SY5Y Cells}

We next sought to investigate the potential functional role of ZNHIT1 in a cellular model of $\alpha$-synucleinopathy; we 
used human SH-SY5Y cells, which are widely used to study molecular and cellular mechanisms of relevance to PD [48]. SH-SY5Y cells were transfected with plasmids expressing either GFP or GFP-tagged wild-type human $\alpha$-Syn, together with either FLAG or FLAG-tagged human ZNHIT1. We examined neurite growth in individual GFP + transfected SH-SY5Y cells at $72 \mathrm{~h}$ post-transfection, to determine whether ZNHIT1 expression could alter the known inhibitory effect of $\alpha$-Syn on neurite growth in these cells [39]. Two-way ANOVA revealed a significant effect of $\alpha$-Syn $\left(F_{1,16}=34.43, p=0.0001\right)$ and of ZNHIT1 $\left(F_{1,16}=18.34\right.$, $p=0.0006$ ) on neurite growth (Fig. 3A, B). Post hoc testing revealed a significant increase in basal levels of neurite growth in the ZNHIT1 + GFP group compared to the control group (Fig. 3A, B). Furthermore, there was a significant reduction in neurite growth in the FLAG $+\alpha$-Syn group that was not seen in the ZNHIT1 $+\alpha$-Syn group (Fig. 3A, B).

Having demonstrated the beneficial effects of ZNHIT1 on neurite growth, we next examined the effects of ZNHIT1 and $\alpha$ Syn on cell viability, which was measured using MTT assay at $72 \mathrm{~h}$ post-transfection. Twoway ANOVA revealed a significant effect of $\alpha$-Syn $\left(F_{1,8}=10.97, p=0.0107\right)$ and ZNHIT1 $\left(F_{1,8}=12.48\right.$, $p=0.0077$ ) on cell viability (Fig. 3C). Post hoc testing revealed a significant reduction in neurite growth the FLAG $+\alpha$-Syn group compared to the control that was not seen in the ZNHIT1 $+\alpha$-Syn group (Fig. 3C). Although the magnitude of these changes were small in the current experiment, it is important to note that the transfection efficiency was approximately $30 \%$ which is likely to mask the true extent of any effect in these cell viability experiments.

To ensure that these effects on neurite growth and cell viability were not due to different levels of ZNHIT1 or $\alpha$-Syn between the groups, we quantified the expression of these proteins by immunocytochemistry followed by densitometry in transfected (GFP + ) cells. These analyses showed equal levels of expression of ZNHIT1 in both groups transfected with ZNHIT1 (Fig. 3D, E), and equal levels of expression of $\alpha$-Syn in both groups transfected with $\alpha$-Syn (Fig. 3F, G). Moreover, in the basal state, overexpression of ZNHIT1 did not alter cellular levels of $\alpha$-Syn, and overexpression of $\alpha$-Syn did not alter cellular levels of ZNHIT1 (Fig. 3D-G). Collectively, these data show that ZNHIT1 regulates basal levels of neurite growth and that overexpression of ZNHIT1 protects
A

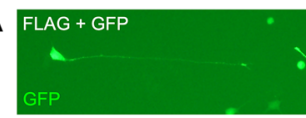

B SH-SY5Y

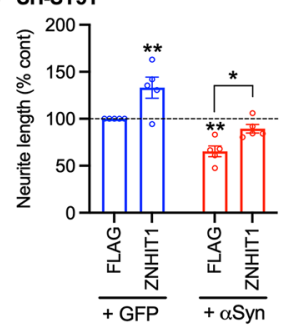

C SH-SY5Y

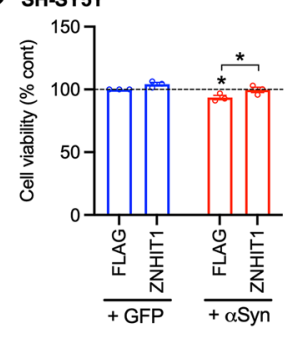

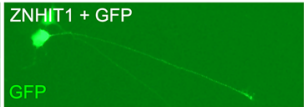

D SH-SY5Y

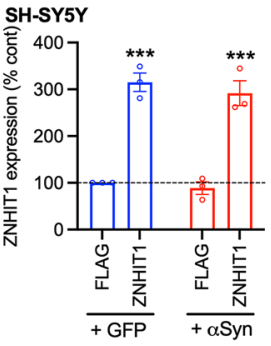

F SH-SY5Y

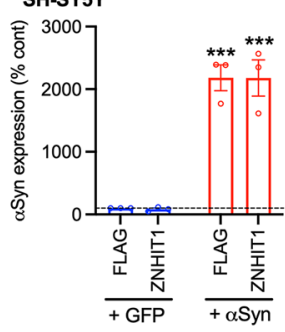

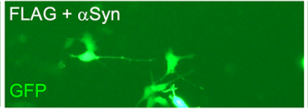

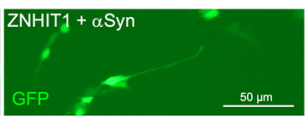

E
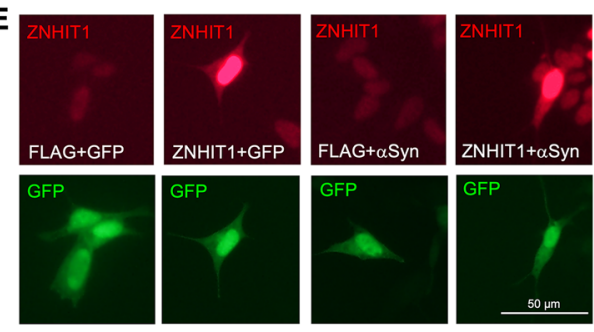

$\mathbf{G}$
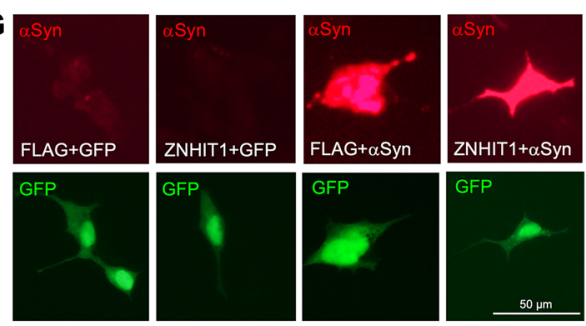

Fig. 3 ZNHIT1 promotes neurite growth and protects against $\alpha$-synuclein-induced reductions in neurite growth and cell viability in SH-SY5Y cells. A Representative photomicrographs, B graph of neurite length and $\mathbf{C}$ graph of cell viability of SH-SY5Y cells transfected with $500 \mathrm{ng}$ of a plasmid expressing either FLAG (Addgene \#31,385) or FLAG-tagged ZNHIT1 (Addgene \#15,332), together with a plasmid expressing either GFP or GFP-tagged wildtype $\alpha$-synuclein ( $\alpha$ Syn) (Addgene \#40,824). All analyses were
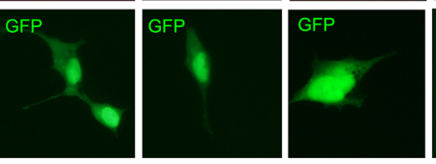

performed at $72 \mathrm{~h}$ post-transfection. D, E Graph and representative photomicrographs showing the relative levels of ZNHIT1 (red) in transfected GFP + cells (green). F, G Graph and representative photomicrographs showing the relative levels of $\alpha$ Syn (red) in transfected $\mathrm{GFP}+$ cells (green). All data are mean \pm SEM expressed as a percentage of the control (FLAG + GFP) from $n=3-6$ independent experiments. Two-way ANOVA with post hoc Fishers LSD test $(* p<0.05$, $* * p<0.01, * * * p<0.001$ vs. FLAG + GFP or as indicated) 
against $\alpha$-Syn-induced reductions in cell viability and neurite growth, without affecting cellular levels of $\alpha$-Syn.

\section{Bioinformatics Analysis Implicates ZNHIT1 Co-expressed Genes in the Regulation of Mitochondrial Function}

We next sought to gain insight into the cellular processes that may be regulated by ZNHIT1. To do this, we performed pair-wise correlations between ZNHIT1 and all other genes expressed in the human SN $(n=101$ samples) using open-source human brain transcriptome data (GSE:60,863) [23]. This analysis identified $n=2248$ genes that were co-expressed with ZNHIT1, after Bonferroni multiple testing correction. We then performed multiple analyses of genes that were strongly co-expressed $(r>0.7)$ with ZNHIT1 in the SN $(n=75)$ using STRING (https://string-db.org). We first generated a protein-protein interaction (PPI) network to determine if there were any biological relationships among this list of genes strongly co-expressed with ZNHIT1. We used a minimum required interaction score of 0.4 which is a 'medium confidence' setting. For the network generated with this list of ZNHIT1 co-expressed genes, the number of nodes was 75, and the number of edges was 53 (Observed $=53$; Expected $=23$ from a random list of the same size), with the PPI network having a PPI enrichment $p$-value of $6.28 \times 10^{-08}$ (Fig. $4 \mathrm{~A}$ ). We next performed a gene set enrichment analysis and found a significant enrichment of genes associated with the multiple GO biological processes (bp) categories linked to mitochondrial function (Fig. 4B). These analyses indicate that ZNHITI co-expressed genes are at least partially biologically connected as a group. When considered along with our neurite growth data shown above, this suggests that cellular levels of ZNHIT1 may regulate the cellular response to $\alpha$-Syn-induced impairments in mitochondrial function.

\section{Bioenergetic State Analysis Shows that Overexpression of ZNHIT1 Prevents a-Synuclein-Induced Impairments in Mitochondrial Function}

To investigate the hypothesis that ZNHIT1 can modulate the cellular response to $\alpha$ Syn-induced impairments in mitochondrial function, we performed an analysis of cellular bioenergetic state. To do this, we measured the oxygen consumption rate $(\mathrm{OCR})$ and individual parameters of respiration in $\mathrm{SH}$ SY5Y cells stably expressing GFP or $\alpha$-Syn, and transfected for $72 \mathrm{~h}$ with either FLAG as a control or FLAG-tagged ZNHIT1 (Fig. 5A-H). Overexpression of $\alpha$-Syn without ZNHIT1 overexpression induced a consistent reduction in OCR when compared to the FLAG + GFP group; this was not seen in the other groups (Fig. 5A). We next examined individual parameters of respiration; two-way ANOVA revealed significant main effects of $\alpha$-Syn on basal respiration $\left(F_{1,12}=8.143, p=0.0145\right)$ (Fig. 5B), maximal respiration $\left(F_{1,12}=9.328, p=0.0100\right)$ (Fig. 5D), spare respiratory capacity $\left(F_{1,12}=5.512, p=0.0369\right)$ (Fig. $\left.5 \mathrm{G}\right)$ and a significant main effect of ZNHIT1 on ATP synthesis $\left(F_{1,12}=6.726\right.$, $p=0.0235$ ) (Fig. 5F). Post hoc analysis revealed significant impairments in basal respiration (Fig. 5B), maximal respiration (Fig. 5D) and spare respiratory capacity (Fig. 5G) in the FLAG $+\alpha$-Syn group that were not seen in the ZNHIT1 $+\alpha$ Syn group. Moreover, higher levels of ATP synthesis were seen in the ZNHIT1 + GFP group compared to the FLAG + GFP control group (Fig. 5F). Collectively, these data show that ZNHIT1 modulates $\alpha$-Syn-impairments in mitochondrial function in SY-SY5Y cells.

\section{Discussion}

In this study, we used gene co-expression analysis to conduct an a priori bioinformatics study to identify genes that are co-expressed with SNCA in the human SN [49].

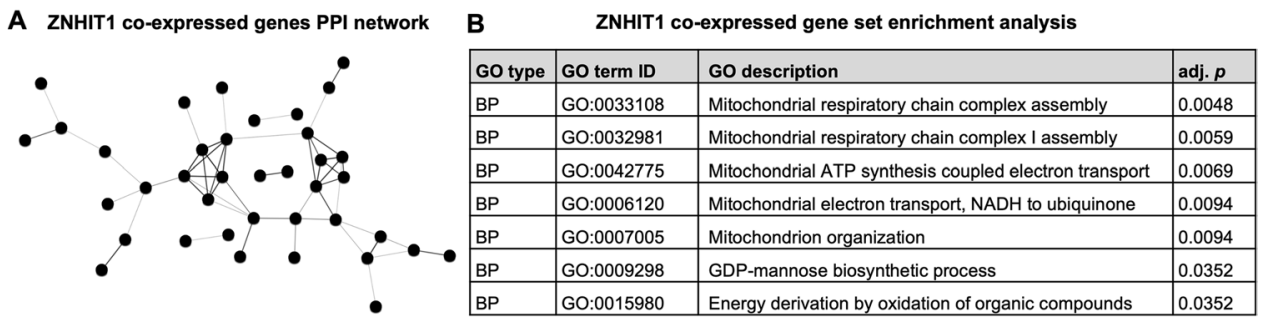

Fig. 4 Bioinformatics analysis implicates ZNHIT1 co-expressed genes in the regulation of mitochondrial function. A Protein-protein interaction (PPI) network generated from the list of genes that were strongly co-expressed $(r>0.7)$ with ZNHIT1 in the human SN. B Table showing the significantly enriched gene ontology (GO) biological processes (bp) categories resulting from a gene set enrichment analysis of ZHNIT1 co-expressed genes. Raw data was derived from GSE:60,863. Gene co-expression analysis was performed using the R2 genomics analysis and visualisation platform (https://hgserver1. amc.nl/cgi-bin/r2/main.cgi). The PPI network and GO analysis were performed using STRING (https://string-db.org) 
Fig. 5 Bioenergetic state analysis shows that overexpression of ZNHIT1 prevents $\alpha$-synucleininduced impairments in mitochondrial function. A Oxygen consumption rate (OCR) in the Seahorse XF Mito Stress Test in SH-SY5Y cells stably expressing GFP or $\alpha$-Syn and transfected for $72 \mathrm{~h}$ with $500 \mathrm{ng}$ of a plasmid expressing either FLAG (Addgene \#31,385) or FLAG-tagged ZNHIT1 (Addgene \#15,332). B-G Graphs of individual parameters of respiration showing $\mathbf{B}$ basal respiration, $\mathbf{C}$ proton leak, D maximal respiration, E non-mitochondrial respiration, $\mathbf{F}$ ATP production, $\mathbf{G}$ spare respiratory capacity and $\mathbf{H}$ coupling efficiency. Data are mean \pm SEM of OCR values normalised to protein content per well from $n=4$ independent replicates. Two-way ANOVA post hoc Fisher's LSD test $(* p<0.05, * * p<0.01 \mathrm{vs}$ FLAG + GFP) or mixed effects model and
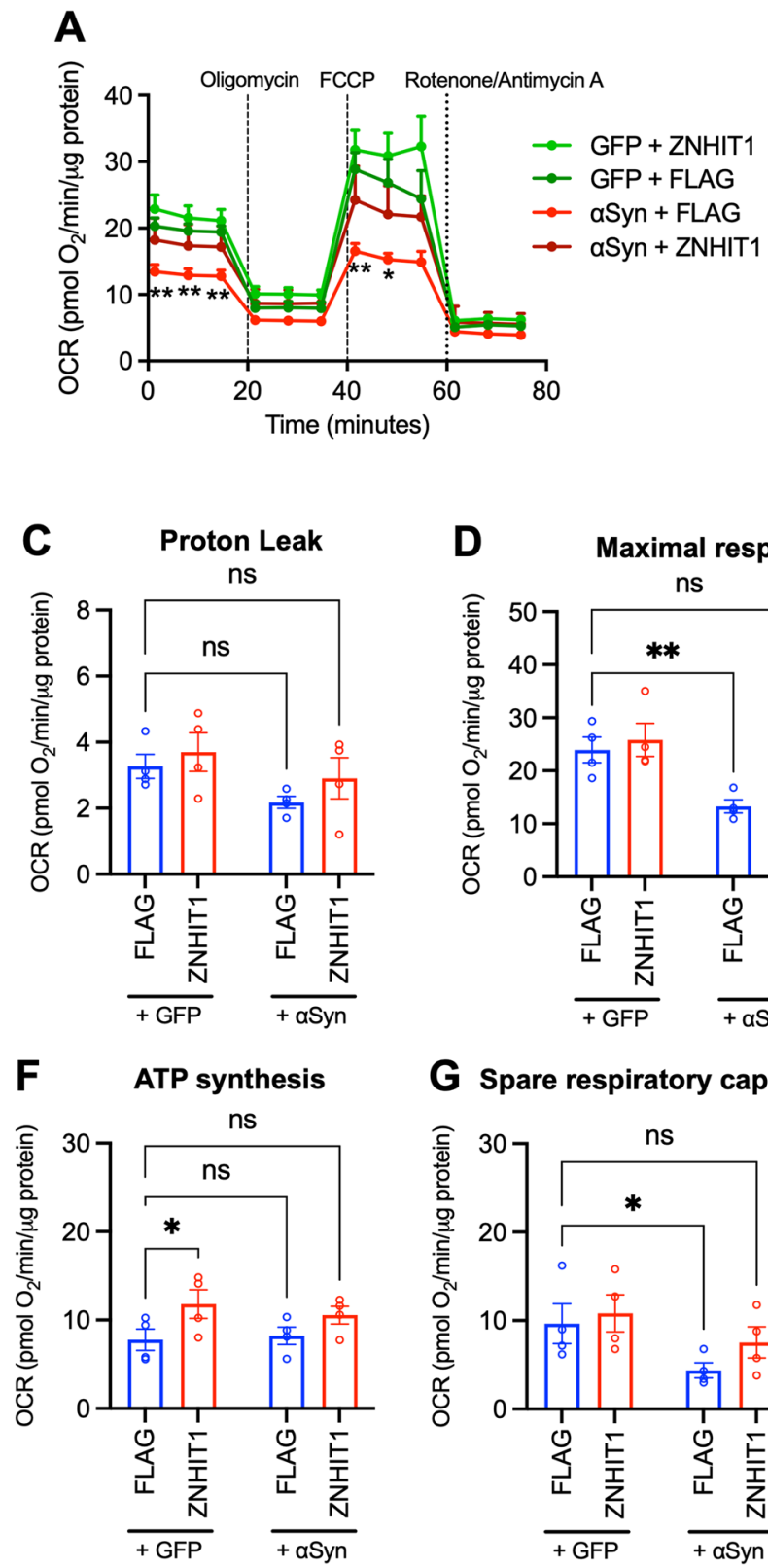

This information formed the basis for subsequent in-depth investigations of underlying molecular events that may be involved in disease pathology in PD. The rationale for this approach is that genes that display significantly correlated co-expression patterns are more likely to be involved in the same cellular pathways and processes, due to their co-regulation [24, 50]. Moreover, co-expression patterns between genes tend to break down in disease states; therefore, such broken correlations can be indicators of pathophysiological molecular dysfunction [24-26]. This type of analysis has been used in many other studies aimed at understanding the molecular basis of cancer [51], schizophrenia [24], chronic fatigue syndrome [52] and Alzheimer's disease (AD) [25]. Using this approach, we identified a significant
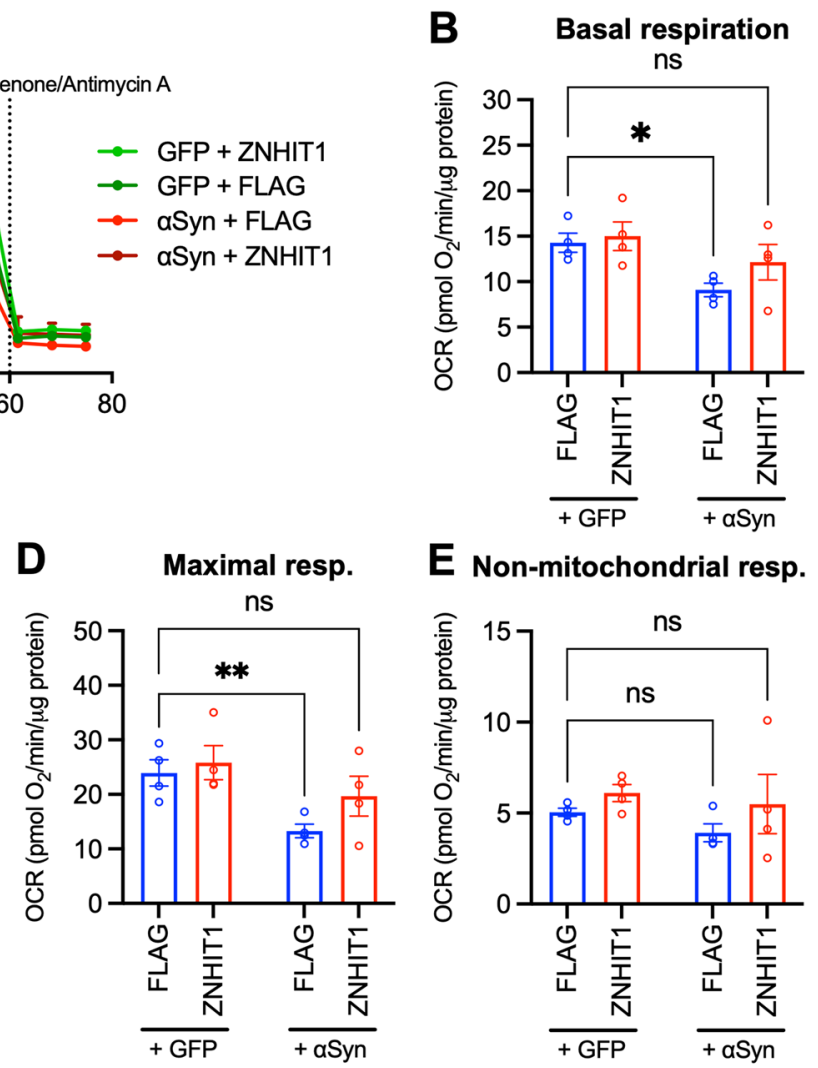

G Spare respiratory capacity

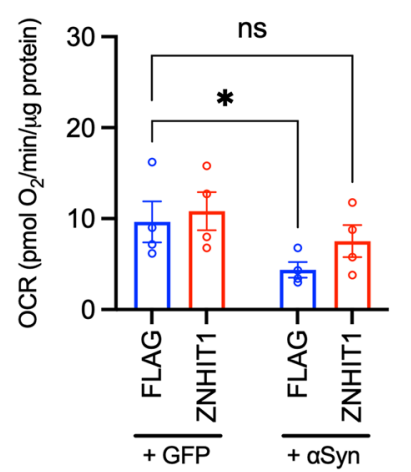

E Non-mitochondrial resp.

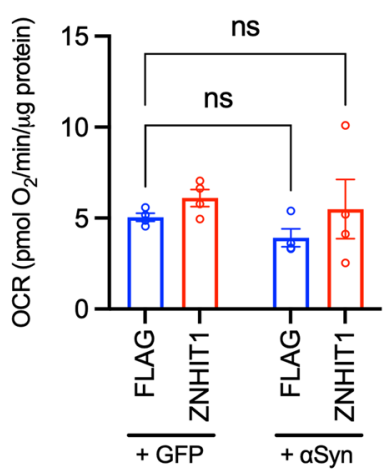

H Coupling efficiency

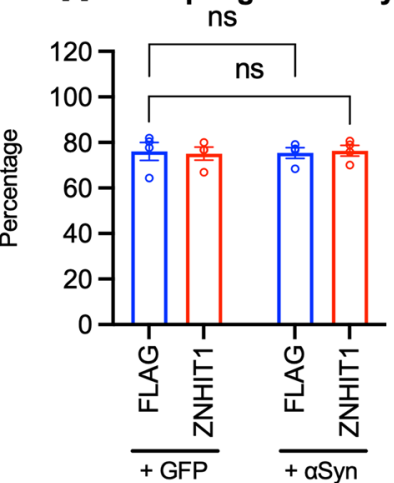

correlation between SNCA and three genes, ZNHIT1, SAP18 and HDAC5, in the SN of control human brain samples. In samples of $\mathrm{SN}$ from PD patients, the positive correlation between $S N C A$ and SAP18 was maintained. However, this correlation was lost between $S N C A$ and both HDAC5 and ZNHIT1, with the greatest loss observed for $S N C A-Z N H I T 1$. As HDAC5 has previously been identified as a regulator of $\alpha$-Syn-induced impairments in neurite growth [38, 39], this highlights the potential of the approach for identifying genes that may be relevant to $\alpha$-Syn-induced cellular dysfunction. Although the function of ZNHIT1 in neural cells was largely unknown, it was the top ranked gene in our analysis which indicated a potential link between ZNHIT1 and $\alpha$-Syn in PD. 
ZNHIT1 is a main regulatory component of the SRCAP complex, which is important in the regulation of chromatin remodelling $[45,46]$. In our study, we found that overexpression of ZNHIT1 increases deposition of the histone variant H2A.Z in SH-SY5Y cells. This agrees with previous studies showing that ZNHIT1 promotes H2A.Z deposition during myocyte differentiation [40]. Furthermore, other studies have reported that ZNHIT1 levels increase during early differentiation of myocytes and mediate the binding of H2A.Z to chromatin in a p38 MAPK-dependent manner [40]. Although the function of ZNHIT1 in neurons is unknown, H2A.Z deposition has been shown to play a role in heterochromatin regulation [41], DNA repair [42, 43] and transcriptional regulation [44]. Of interest, in LUHMES cells, overexpression of WT or A30P mutant $\alpha$-Syn leads to downregulation of DNA repair genes [53], which contrasts with its action to stimulate H2A.Z deposition found in our study. We further found that ZNHIT1-induced H2A.Z incorporation is unaffected by overexpression of $\alpha$-Syn, suggesting that ZNHIT1 may be able to protect against the detrimental cellular effects of $\alpha$-Syn.

To test this hypothesis, we used $\alpha$-Syn-induced reductions in SH-SY5Y cell survival and neurite growth as readouts of cellular pathology of relevance to PD. The rationale for this is that neurite degeneration is recognised as a core component of the cellular pathology of PD [1, 54], and further that both overexpression of $\alpha$-Syn in rodent dopaminergic neurons [17] and mutation of $\alpha$-Syn in iPSC-derived dopaminergic neurons result in reductions in cell survival and neurite growth $[18,19]$. We found that the overexpression of ZNHIT1 significantly increased basal levels of neurite growth and protected SH-SY5Y cells against the adverse effects of overexpression of $\alpha$ Syn-on neurite growth and cell viability. We found that the overexpression of ZNHIT1 did not alter cellular levels of $\alpha$-Syn and conversely that the overexpression of $\alpha$-Syn did not affect cellular levels of ZNHIT1 in SH-SY5Y cells. This shows that the beneficial effects of ZNHIT1 overexpression are not secondary to an effect of ZNHIT1 in reducing cellular levels of $\alpha$-Syn. Collectively, these data identify ZNHIT1 as a novel regulator of neurite growth that protects against the detrimental effects of $\alpha$-Syn on neurite growth and cell viability.

To gain insight into the gene regulatory networks that may be influenced by ZNHIT1, we used gene co-expression analysis to identify ZNHIT1 co-expressed genes. This revealed a significant enrichment of genes associated with mitochondrial function in the human SN, suggesting that ZNHIT1 co-expressed genes are biologically connected as a group and may function as regulators of mitochondrial function. This finding is supported by a previous study showing that ZNHIT1 regulates the expression of genes associated with mitochondrial function during prenatal cardiac development [29]. This is important since mitochondrial dysfunction has been implicated as a key component in the pathogenesis of PD [for review see: 55]. Furthermore, $\alpha$-Syn has been shown to impair mitochondrial function [see review: 56]. For example, outer mitochondrial membrane proteins, such as voltage-dependent anion-selective channel 1 (VDAC1) [57], translocase of the outer membrane 20 (TOM20) [58] and TOM40 [59], are bound by $\alpha$-Syn, leading to mitochondrial dysfunction [for review see: 55]. Given the beneficial effects of ZNHIT1 overexpression on neurite growth and cell survival, and the fact that ZNHIT1 co-expressed genes were enriched in those associated with mitochondrial function, this suggested that ZNHIT1 may modulate $\alpha$-Syn-induced mitochondrial dysfunction.

In agreement with this hypothesis, bioenergetic state analysis revealed that overexpression of $\alpha$-Syn resulted in a consistent reduction in OCR, as well as significant impairments in basal respiration, maximal respiration and spare respiratory capacity in SH-SY5Y cells stably expressing $\alpha$-Syn. This agrees with previous studies showing $\alpha$-Syninduced impairments in mitochondrial function [for reviews see: 60,61$]. \alpha$-Syn has been shown to have a neuroprotective role in maintaining mitochondrial function [60]; however, in disease states such as PD, toxic $\alpha$-Syn aggregates form as a result of synaptotoxicity and synaptic dysfunction [54], leading to defects in mitochondrial function [for review see: 55]. Interestingly, we found that $\alpha$-Syn-induced impairments in mitochondrial function were not seen in ZNHIT1-overexpressing cells, suggesting that ZNHIT1 overexpression is sufficient to prevent the effects of $\alpha$-Syn on mitochondria. Moreover, we found that ZNHIT1 overexpression resulted in a significant increase in ATP synthesis. This finding is consistent with a previous report showing that ATP production was reduced in cardiac tissue of ZNHIT1 knockout mice and that ZNHIT1 was crucial for maintaining the integrity of mitochondrial respiratory complex in cardiac cells [29]. This suggests that ZNHIT1 may be important for maintaining mitochondrial function in dopaminergic neurons in the SN.

In summary, our findings have identified an enrichment of genes co-expressed with SNCA in the SN that are involved in histone deacetylation. In particular, we report loss of co-expression of ZNHIT1 and SNCA in PD, which is indicative of functional dysregulation. We also show that ZNHIT1 increases incorporation of the histone variant H2A.Z in SH-SY5Y cells. Functional studies revealed a neuroprotective effect of ZNHIT1 overexpression against $\alpha$-Syn-induced reductions in neurite growth and cell viability, as well as mitochondrial function, in SH-SY5Y cells. Taken together, our data reveal ZNHIT1 as a potential novel therapeutic target for neuroprotection in PD.

Supplementary Information The online version contains supplementary material available at https://doi.org/10.1007/s12035-022-02768-9. 
Author Contribution All authors contributed to the study conception and design. Erin McCarthy carried out the cell culture work. Erin McCarthy and Gerard O'Keeffe carried out the bioinformatics analysis. Martina Mazzocchi generated the stable cell lines. Aaron Barron carried out the Seahorse experiments. Noelia Morales-Prieto, Cathal McCarthy, Louise Collins, Aideen Sullivan and Gerard O'Keeffe supervised the work. All authors edited and co-wrote the manuscript.

Funding Open Access funding provided by the IReL Consortium. This publication has emanated from research conducted with the financial support of Science Foundation Ireland (SFI) under grant number 19/FFP/6666 (G.O'K.) and the Irish Research Council ((GOIPG2018-2795; E.Mc/L.C./A.S./G.O'K), (GOIPG/2019/4400; A.B./C. Mc/G.O'K) and (GOIPG/2017/945; M.M./A.S./G.O'K)) and the Marie Skłodowska-Curie Fellowship programme under grant number MSCAIF-2019 890290 (N.M.P/A.S./G'O.K).

Availability of Data and Material All data generated during this study are included in this article or are available on reasonable request from the corresponding authors.

\section{Declarations}

Ethics Approval The bioinformatics work was conducted using opensource transcriptome data. SH-SY5Y cells are commercially available and no ethics approval was required.

Consent to Participate Not applicable to this study.

Consent for Publication Not applicable to this study.

Conflict of Interest The authors declare no competing interests.

Open Access This article is licensed under a Creative Commons Attribution 4.0 International License, which permits use, sharing, adaptation, distribution and reproduction in any medium or format, as long as you give appropriate credit to the original author(s) and the source, provide a link to the Creative Commons licence, and indicate if changes were made. The images or other third party material in this article are included in the article's Creative Commons licence, unless indicated otherwise in a credit line to the material. If material is not included in the article's Creative Commons licence and your intended use is not permitted by statutory regulation or exceeds the permitted use, you will need to obtain permission directly from the copyright holder. To view a copy of this licence, visit http://creativecommons.org/licenses/by/4.0/.

\section{References}

1. Kordower JH, Olanow CW, Dodiya HB, Chu Y, Beach TG, Adler CH, Halliday GM, Bartus RT (2013) Disease duration and the integrity of the nigrostriatal system in Parkinson's disease. Brain 136(Pt 8):2419-2431. https://doi.org/10.1093/brain/awt192

2. Lees AJ, Hardy J, Revesz T (2009) Parkinson's disease. Lancet 373(9680):2055-2066. https://doi.org/10.1016/S0140-6736(09) 60492-X

3. Armstrong MJ, Okun MS (2020) Diagnosis and treatment of Parkinson disease: a review. JAMA 323(6):548-560. https://doi.org/ 10.1001/jama.2019.22360

4. Bloem BR, Okun MS, Klein C (2021) Parkinson's disease. Lancet 397(10291):2284-2303. https://doi.org/10.1016/S0140-6736(21) 00218-X
5. Spillantini MG, Crowther RA, Jakes R, Hasegawa M, Goedert M (1998) alpha-Synuclein in filamentous inclusions of Lewy bodies from Parkinson's disease and dementia with lewy bodies. Proc Natl Acad Sci U S A 95(11):6469-6473. https://doi.org/10.1073/ pnas.95.11.6469

6. Spillantini MG, Schmidt ML, Lee VM, Trojanowski JQ, Jakes R, Goedert M (1997) Alpha-synuclein in Lewy bodies. Nature 388(6645):839-840. https://doi.org/10.1038/42166

7. Braak H, Sandmann-Keil D, Gai W, Braak E (1999) Extensive axonal Lewy neurites in Parkinson's disease: a novel pathological feature revealed by alpha-synuclein immunocytochemistry. Neurosci Lett 265(1):67-69. https://doi.org/10.1016/s0304-3940(99) 00208-6

8. Polymeropoulos MH, Lavedan C, Leroy E, Ide SE, Dehejia A, Dutra A, Pike B, Root H, Rubenstein J, Boyer R, Stenroos ES, Chandrasekharappa S, Athanassiadou A, Papapetropoulos T, Johnson WG, Lazzarini AM, Duvoisin RC, Di Iorio G, Golbe LI, Nussbaum RL (1997) Mutation in the alpha-synuclein gene identified in families with Parkinson's disease. Science 276(5321):2045-2047. https://doi.org/10.1126/science.276. 5321.2045

9. Kruger R, Kuhn W, Muller T, Woitalla D, Graeber M, Kosel S, Przuntek H, Epplen JT, Schols L, Riess O (1998) Ala30Pro mutation in the gene encoding alpha-synuclein in Parkinson's disease. Nat Genet 18(2):106-108. https://doi.org/10.1038/ ng0298-106

10. Singleton AB, Farrer M, Johnson J, Singleton A, Hague S, Kachergus J, Hulihan M, Peuralinna T, Dutra A, Nussbaum R, Lincoln S, Crawley A, Hanson M, Maraganore D, Adler C, Cookson MR, Muenter M, Baptista M, Miller D, Blancato J, Hardy J, GwinnHardy K (2003) alpha-Synuclein locus triplication causes Parkinson's disease. Science 302(5646):841. https://doi.org/10.1126/ science. 1090278

11. Nishioka K, Hayashi S, Farrer MJ, Singleton AB, Yoshino H, Imai H, Kitami T, Sato K, Kuroda R, Tomiyama H, Mizoguchi K, Murata M, Toda T, Imoto I, Inazawa J, Mizuno Y, Hattori N (2006) Clinical heterogeneity of alpha-synuclein gene duplication in Parkinson's disease. Ann Neurol 59(2):298-309. https://doi.org/ 10.1002/ana.20753

12. Guo Y, Sun Y, Song Z, Zheng W, Xiong W, Yang Y, Yuan L, Deng $\mathrm{H}$ (2021) Genetic analysis and literature review of SNCA variants in Parkinson's disease. Front Aging Neurosci 13:648151. https:// doi.org/10.3389/fnagi.2021.648151

13. Book A, Guella I, Candido T, Brice A, Hattori N, Jeon B, Farrer MJ, Consortium SMIotG (2018) A meta-analysis of alphasynuclein multiplication in familial Parkinsonism. Front Neurol 9:1021. https://doi.org/10.3389/fneur.2018.01021

14. Maraganore DM, de Andrade M, Elbaz A, Farrer MJ, Ioannidis JP, Kruger R, Rocca WA, Schneider NK, Lesnick TG, Lincoln SJ, Hulihan MM, Aasly JO, Ashizawa T, Chartier-Harlin MC, Checkoway H, Ferrarese C, Hadjigeorgiou G, Hattori N, Kawakami H, Lambert JC, Lynch T, Mellick GD, Papapetropoulos S, Parsian A, Quattrone A, Riess O, Tan EK, Van Broeckhoven C, Genetic Epidemiology of Parkinson's Disease C (2006) Collaborative analysis of alpha-synuclein gene promoter variability and Parkinson disease. JAMA 296(6):661-670. https://doi.org/10.1001/jama.296.6. 661

15. Mueller JC, Fuchs J, Hofer A, Zimprich A, Lichtner P, Illig T, Berg D, Wullner U, Meitinger T, Gasser T (2005) Multiple regions of alpha-synuclein are associated with Parkinson's disease. Ann Neurol 57(4):535-541. https://doi.org/10.1002/ana.20438

16. Mizuta I, Satake W, Nakabayashi Y, Ito C, Suzuki S, Momose Y, Nagai Y, Oka A, Inoko H, Fukae J, Saito Y, Sawabe M, Murayama S, Yamamoto M, Hattori N, Murata M, Toda T (2006) Multiple candidate gene analysis identifies alpha-synuclein as a 
susceptibility gene for sporadic Parkinson's disease. Hum Mol Genet 15(7):1151-1158. https://doi.org/10.1093/hmg/dd1030

17. Koch JC, Bitow F, Haack J, d'Hedouville Z, Zhang JN, Tonges L, Michel U, Oliveira LM, Jovin TM, Liman J, Tatenhorst L, Bahr M, Lingor P (2015) Alpha-Synuclein affects neurite morphology, autophagy, vesicle transport and axonal degeneration in CNS neurons. Cell Death Dis 6:e1811. https://doi.org/10.1038/cddis.2015. 169

18. Kouroupi G, Taoufik E, Vlachos IS, Tsioras K, Antoniou N, Papastefanaki F, Chroni-Tzartou D, Wrasidlo W, Bohl D, Stellas D, Politis PK, Vekrellis K, Papadimitriou D, Stefanis L, Bregestovski P, Hatzigeorgiou AG, Masliah E, Matsas R (2017) Defective synaptic connectivity and axonal neuropathology in a human iPSC-based model of familial Parkinson's disease. Proc Natl Acad Sci U S A 114(18):E3679-E3688. https://doi.org/10.1073/pnas. 1617259114

19. Oliveira LM, Falomir-Lockhart LJ, Botelho MG, Lin KH, Wales $\mathrm{P}$, Koch JC, Gerhardt E, Taschenberger H, Outeiro TF, Lingor P, Schule B, Arndt-Jovin DJ, Jovin TM (2015) Elevated alphasynuclein caused by SNCA gene triplication impairs neuronal differentiation and maturation in Parkinson's patient-derived induced pluripotent stem cells. Cell Death Dis 6:e1994. https://doi.org/10. 1038/cddis.2015.318

20. Gomez-Benito M, Granado N, Garcia-Sanz P, Michel A, Dumoulin M, Moratalla R (2020) Modeling Parkinson's disease with the alpha-synuclein protein. Front Pharmacol 11:356. https://doi.org/ 10.3389/fphar.2020.00356

21. van Dam S, Vosa U, van der Graaf A, Franke L, de Magalhaes JP (2018) Gene co-expression analysis for functional classification and gene-disease predictions. Brief Bioinform 19(4):575-592. https://doi.org/10.1093/bib/bbw139

22. Yin W, Mendoza L, Monzon-Sandoval J, Urrutia AO, Gutierrez H (2021) Emergence of co-expression in gene regulatory networks. PLoS ONE 16(4):e0247671. https://doi.org/10.1371/journal.pone. 0247671

23. Ramasamy A, Trabzuni D, Guelfi S, Varghese V, Smith C, Walker R, De T, Consortium UKBE, North American Brain Expression C, Coin L, de Silva R, Cookson MR, Singleton AB, Hardy J, Ryten M, Weale ME (2014) Genetic variability in the regulation of gene expression in ten regions of the human brain. Nat Neurosci 17(10):1418-1428. https://doi.org/10.1038/nn.3801

24. Torkamani A, Dean B, Schork NJ, Thomas EA (2010) Coexpression network analysis of neural tissue reveals perturbations in developmental processes in schizophrenia. Genome Res 20(4):403-412

25. Zhang B, Gaiteri C, Bodea L-G, Wang Z, McElwee J, Podtelezhnikov AA, Zhang C, Xie T, Tran L, Dobrin R (2013) Integrated systems approach identifies genetic nodes and networks in lateonset Alzheimer's disease. Cell 153(3):707-720

26. Southworth LK, Owen AB, Kim SK (2009) Aging mice show a decreasing correlation of gene expression within genetic modules. PLoS genetics 5(12): 1000776

27. Wong MM, Cox LK, Chrivia JC (2007) The chromatin remodeling protein, SRCAP, is critical for deposition of the histone variant H2A.Z at promoters. J Biol Chem 282(36):26132-26139. https:// doi.org/10.1074/jbc.M703418200

28. Watanabe S, Radman-Livaja M, Rando OJ, Peterson CL (2013) A histone acetylation switch regulates H2A.Z deposition by the SWR-C remodeling enzyme. Science 340(6129):195-199. https:// doi.org/10.1126/science. 1229758

29. Xu M, Yao J, Shi Y, Yi H, Zhao W, Lin X, Yang Z (2021) The SRCAP chromatin remodeling complex promotes oxidative metabolism during prenatal heart development. Development 148 (8). https://doi.org/10.1242/dev.199026

30. Zhao B, Chen Y, Jiang N, Yang L, Sun S, Zhang Y, Wen Z, Ray L, Liu H, Hou G, Lin X (2019) Znhit1 controls intestinal stem cell maintenance by regulating H2A.Z incorporation. Nat Commun 10(1):1071. https://doi.org/10.1038/s41467-019-09060-w

31. Ramasamy A, Trabzuni D, Guelfi S, Varghese V, Smith C, Walker R, De T, Coin L, De Silva R, Cookson MR (2014) Genetic variability in the regulation of gene expression in ten regions of the human brain. Nat Neurosci 17(10):1418-1428

32. http://r2.amc.nl R2: Genomics Analysis and Visualization Platform. Jan Koster. http://r2.amc.nl

33. Xicoy H, Wieringa B, Martens GJ (2017) The SH-SY5Y cell line in Parkinson's disease research: a systematic review. Mol Neurodegener 12(1):1-11

34. Furlong RA, Narain Y, Rankin J, Wyttenbach A, Rubinsztein DC (2000) $\alpha$-Synuclein overexpression promotes aggregation of mutant huntingtin. Biochem J 346(3):577-581

35. Cai Y, Jin J, Florens L, Swanson SK, Kusch T, Li B, Workman JL, Washburn MP, Conaway RC, Conaway JW (2005) The mammalian YL1 protein is a shared subunit of the TRRAP/TIP60 histone acetyltransferase and SRCAP complexes. J Biol Chem 280(14):13665-13670

36. Dmitriev PV, Vassetzky YS (2008) A set of vectors for introduction of antibiotic resistance genes by in vitro Cre-mediated recombination. BMC Res Notes 1(1):1-10

37. Dijkstra AA, Ingrassia A, de Menezes RX, van Kesteren RE, Rozemuller AJ, Heutink P, van de Berg WD (2015) Evidence for immune response, axonal dysfunction and reduced endocytosis in the substantia nigra in early stage Parkinson's disease. PLoS ONE 10(6):e0128651. https://doi.org/10.1371/journal.pone.0128651

38. Mazzocchi M, Goulding SR, Wyatt SL, Collins LM, Sullivan AM, O'Keeffe GW (2021) LMK235, a small molecule inhibitor of HDAC4/5, protects dopaminergic neurons against neurotoxinand alpha-synuclein-induced degeneration in cellular models of Parkinson's disease. Mol Cell Neurosci 115:103642. https://doi. org/10.1016/j.mcn.2021.103642

39. Mazzocchi M, Wyatt SL, Mercatelli D, Morari M, Morales-Prieto N, Collins LM, Sullivan AM, O'Keeffe GW (2019) Gene coexpression analysis identifies histone deacetylase 5 and 9 expression in midbrain dopamine neurons and as regulators of neurite growth via bone morphogenetic protein signaling. Front Cell Dev Biol 7:191. https://doi.org/10.3389/fcell.2019.00191

40. Cuadrado A, Corrado N, Perdiguero E, Lafarga V, Muñoz-Canoves P, Nebreda AR (2010) Essential role of p18Hamlet/SRCAPmediated histone H2A. Z chromatin incorporation in muscle differentiation. EMBO J 29(12):2014-2025

41. Rangasamy D, Berven L, Ridgway P, Tremethick DJ (2003) Pericentric heterochromatin becomes enriched with $\mathrm{H} 2 \mathrm{~A}$. Z during early mammalian development. EMBO J 22(7):1599-1607

42. Nishibuchi I, Suzuki H, Kinomura A, Sun J, Liu N-A, Horikoshi Y, Shima H, Kusakabe M, Harata M, Fukagawa T (2014) Reorganization of damaged chromatin by the exchange of histone variant H2A. Z-2. Int J Radiat Oncol Biol Phys 89(4):736-744

43. Xu Y, Ayrapetov MK, Xu C, Gursoy-Yuzugullu O, Hu Y, Price BD (2012) Histone H2A. Z controls a critical chromatin remodeling step required for DNA double-strand break repair. Mol Cell 48(5):723-733

44. Draker R, Ng MK, Sarcinella E, Ignatchenko V, Kislinger T, Cheung P (2012) A combination of H2A. Z and H4 acetylation recruits $\mathrm{Brd} 2$ to chromatin during transcriptional activation. PLoS Genet 8(11):e1003047

45. Liang X, Shan S, Pan L, Zhao J, Ranjan A, Wang F, Zhang Z, Huang Y, Feng H, Wei D (2016) Structural basis of H2A. Z recognition by SRCAP chromatin-remodeling subunit YL1. Nat Struct Mol Biol 23(4):317-323

46. Ye B, Liu B, Yang L, Huang G, Hao L, Xia P, Wang S, Du Y, Qin X, Zhu P (2017) Suppression of SRCAP chromatin remodelling complex and restriction of lymphoid lineage commitment by Pcid2. Nat Commun 8(1):1-14 
47. Kontopoulos E, Parvin JD, Feany MB (2006) $\alpha$-synuclein acts in the nucleus to inhibit histone acetylation and promote neurotoxicity. Hum Mol Genet 15(20):3012-3023

48. Xicoy H, Wieringa B, Martens GJ (2017) The SH-SY5Y cell line in Parkinson's disease research: a systematic review. Mol Neurodegener 12(1):10. https://doi.org/10.1186/s13024-017-0149-0

49. Van Dam S, Vosa U, van der Graaf A, Franke L, de Magalhaes JP (2018) Gene co-expression analysis for functional classification and gene-disease predictions. Brief Bioinform 19(4):575-592

50. Weirauch MT (2011) Gene coexpression networks for the analysis of DNA microarray data. Appl Stat Netw Biol Methods Syst Biol $1: 215-250$

51. Horvath S, Zhang B, Carlson M, Lu K, Zhu S, Felciano R, Laurance M, Zhao W, Qi S, Chen Z (2006) Analysis of oncogenic signaling networks in glioblastoma identifies ASPM as a molecular target. Proc Natl Acad Sci 103(46):17402-17407

52. Presson AP, Sobel EM, Papp JC, Suarez CJ, Whistler T, Rajeevan MS, Vernon SD, Horvath S (2008) Integrated weighted gene coexpression network analysis with an application to chronic fatigue syndrome. BMC Syst Biol 2(1):1-21

53. Paiva I, Pinho R, Pavlou MA, Hennion M, Wales P, Schutz AL, Rajput A, Szego EM, Kerimoglu C, Gerhardt E, Rego AC, Fischer A, Bonn S, Outeiro TF (2017) Sodium butyrate rescues dopaminergic cells from alpha-synuclein-induced transcriptional deregulation and DNA damage. Hum Mol Genet 26(12):2231-2246. https://doi.org/10.1093/hmg/ddx114

54. O'Keeffe GW, Sullivan AM (2018) Evidence for dopaminergic axonal degeneration as an early pathological process in Parkinson's disease. Parkinsonism Relat Disord 56:9-15

55. Park J-S, Davis RL, Sue CM (2018) Mitochondrial dysfunction in Parkinson's disease: new mechanistic insights and therapeutic perspectives. Curr Neurol Neurosci Rep 18(5):1-11
56. Pozo Devoto VM, Falzone TL (2017) Mitochondrial dynamics in Parkinson's disease: a role for $\alpha$-synuclein? Dis Model Mech 10(9):1075-1087

57. Martin LJ, Semenkow S, Hanaford A, Wong M (2014) The mitochondrial permeability transition pore regulates Parkinson's disease development in mutant $\alpha$-synuclein transgenic mice. Neurobiol Aging 35(5):1132-1152

58. Di Maio R, Barrett PJ, Hoffman EK, Barrett CW, Zharikov A, Borah A, Hu X, McCoy J, Chu CT, Burton EA (2016) $\alpha$-Synuclein binds to TOM20 and inhibits mitochondrial protein import in Parkinson's disease. Sci Transl Medicine 8(342):342ra378

59. Bender A, Desplats P, Spencer B, Rockenstein E, Adame A, Elstner M, Laub C, Mueller S, Koob AO, Mante M (2013) TOM40 mediates mitochondrial dysfunction induced by $\alpha$-synuclein accumulation in Parkinson's disease. PloS one 8(4):e62277

60. Faustini G, Marchesan E, Zonta L, Bono F, Bottani E, Longhena F, Ziviani E, Valerio A, Bellucci A (2019) Alpha-synuclein preserves mitochondrial fusion and function in neuronal cells. Oxid Med Cell Longev 2019

61. Serratos IN, Hernández-Pérez E, Campos C, Aschner M, Santamaría A (2021) An Update on the critical role of $\alpha$-synuclein in Parkinson's disease and other synucleinopathies: from tissue to cellular and molecular levels. Mol Neurobiol. https://doi.org/10. 1007/s12035-021-02596-3

Publisher's Note Springer Nature remains neutral with regard to jurisdictional claims in published maps and institutional affiliations. 